\title{
Research on Dyeing Process for Polyamide with Aqueous Extracted from the Fruits of Diospyros Mollis
}

\author{
Hong Phuong Pham Thi ${ }^{1}$, Linh Hoang Thi ${ }^{2}$, TrungKien Tran ${ }^{3}$ and Thu Lan Nguyen Thi ${ }^{4}$ \\ 1. Chemical Engineering Faculty, Industrial University of Ho Chi Minh City, HCMC 7000000, Vietnam \\ 2. Faculty of Technology of Textile and Fashion, Hung Yen University of Technology and Education, Hung Yen Province 160000, \\ Vietnam \\ 3. School of Chemical Engineering, Hanoi University of Science and Technology, Ha Noi City 100000, Vietnam \\ 4. Faculty of Textiles and Leather, University of Economic and Technical Industries, Ha Noi City 100000, Vietnam
}

\begin{abstract}
In this study, polyamide fabrics were dyed with aqueous extracts from Diospyros Mollis fruits. The aqueous extracts from Diospyros Mollis fruits were extracted with water solution at room temperature and a ratio of 1:5 for Diospyros Mollis to water. The influences of temperature in range of $50-100{ }^{\circ} \mathrm{C}$, time in range of $30-80$ minutes and a ratio of aqueous extracts to water in range of 3/1-1/11 were investigated. The results showed that the aqueous extracts from Diospyros Mollis fruits could dye polyamide fabrics to have black color with color strength and fastness properties to be very good level of 4-5.
\end{abstract}

Key words: Polyamide, natural dyes, Diospyros Mollis fruit.

\section{Introduction}

In recent years, the rapid growth of the industry and the human precede resource depletion and environmental pollution, including textile. So the problem using dyes derived naturally from plants, fruits, flowers, leaves... alternative to synthetic dyes are essential. The study used the results wore likewise a source of available natural ingredients and is a source of waste. In addition, it is used as black dye and no any other application, and when ripe fruit will fall, it become sources of waste. Simultaneously, research processes dyeing extracts from wearing likewise result in two types of materials are natural and synthetic silk and polyamide exhaust dyeing method, hoping the research results can be applied to reality and contribute section on cleaner production technologies and sustainable development Diospyros Mollis griffis a shrub growing in South-east Asian countries and bears the fruits of $2-2.5 \mathrm{~cm}$ in diameter

Corresponding author: Hong Phuong Pham Thi, Ph.D., research fields: natural compound, natural dye, and organic synthetic. in summer [1]. The extracts of the fresh fruits are used in Vietnam as a natural black dye in textile applications and a readily oxidizable phenolic constituent, named Diospyrol. Diospyrol is very sensitive to air and turn black. Beside, the process of the formation of black pigment is assumed to be rather complicated, including polymerization due to phenol radical coupling, quinone-phenol rearrangement and formation of charge-transfer complex between phenols and quinons, etc.. Therefore, Diospyros Mollis Griff can be used for dyeing textile materials [2].

\section{Materials and Methodology}

\subsection{Materials}

Diospyros Mollis were picked from the parks in Ho Chi Minh City. Polyamide fabrics have sourced from Formosa Company.

\subsection{Methodology}

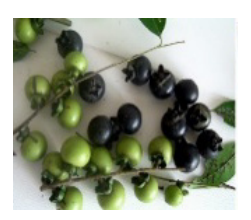


Green Diospyros Mollis fruits were collected and stored in the refrigerator for 5 to 7 days. Diospyros Mollis is extracted by pureed in water with a ratio of fruit/water of $1 / 5$ at room temperature in 60 minutes, and then taken away residue by filtration obtained pale yellow. Polyamide fabric has been treated, and prepared the sample size to dye $(10 \times 20 \mathrm{~cm})$, observing the factors influence of dye process, and then has been dyed for 3 times. After dyeing, it was carried out warm washing at $50{ }^{\circ} \mathrm{C}$ with soap solution $1 \mathrm{~g} / \mathrm{L}$ and $\mathrm{Na}_{2} \mathrm{CO}_{3} 1 \mathrm{~g} / \mathrm{L}$ in 5 minutes, then rinsing and drying by natural light. This study only observe 3 factors, which are time (30-80 mins), temperature (50-100 ${ }^{\circ} \mathrm{C}$ ), and andrate dyeing (aqueous of Diospyros Mollis extract/water, 3/1-1/11, equivalent to $8.3 \%-75 \%$ aqueous extract of Diospyros Mollisin dyeing solution). The results of the study were evaluated by determining color intensity and color fastness of dyed silk fabric in color CIELAB system by Minolta CR 300 colorimeter machine, Japan 73180167 [3].

Factorial experimental planning design: The model selected for this study is orthogonal center of complex pattern. Three variables were selected to study temperature dyeing $\left({ }^{\circ} \mathrm{C}\right)$, time dyeing (minutes) and rate dyeing; the objective functionis was selected as the mínimum value of color saturation on dyed polyamide fabric to obtain black color and high fastness of dyed polyamide fabric. Using software Statgraphics Centurion XV.II to build regression equations and computational processingunit could find optimal dyeing technology [4]. Quadratic Eq. (1) shows the correlation between the intensity of color and the influence factors in this study:

$$
\begin{array}{r}
Y=y_{1}=b_{0}+b_{1} x_{1}+\cdots+b_{k} x_{k}+b_{12} x_{1} x_{2} \\
+\cdots+b_{11} x_{1}^{2}+\cdots+b_{k k} x_{k}^{2}
\end{array}
$$

where $\mathrm{Y}$ is the color intensity or the color saturation; $\mathrm{x}_{1}, \mathrm{x}_{2}$ are variables; $\mathrm{b}_{0}, \mathrm{~b}_{1}, \mathrm{~b}_{2}, \mathrm{~b}_{11}, \mathrm{~b}_{12}, \mathrm{~b}_{22}$ are the regression coefficients, representing the impact of the variable to the objective functionis and the color intensity [5].
Test the dyed polyamide: The standard of fastness are color fastness to washing (ISO 105- C06 A1S-02), color fastness to clorine (ISO 105-E03-94), color fastness to perspiration (ISO 105E04-2008), breaking load and stretch bandages off (ISO 1394-1-99), tearing (ISO 13937-1-00), wet friction resistance and dry friction (ISO105-X12-01), and ecological check by testing the amount of azo and formadehyde (ISO 14180-2011) [6].

\section{Results and Discussion}

\subsection{Affect of the Solution Extracted from Diospyros Mollis on Polyamide}

\section{Effect of temperature dyeing on the color saturation} of polyamide fabric: Figs. 1(a-c) shows that as temperature increased from $50-100{ }^{\circ} \mathrm{C}$, the color saturation of dyed polmide was decreasing 4.3-2.47 and obtained darker black color gradually. At 50-70 ${ }^{\circ} \mathrm{C}$ the color of fabric did not change much, while in $80-100{ }^{\circ} \mathrm{C}$, the color of fabric began to change. This may be explained that at low temperature, the color saturation does not change much beause the structure of polyamide fiber has not yet fully open, and the reaction fixation of colorant have not yet occur. But when temperature rise to $90{ }^{\circ} \mathrm{C}$, the capillary of polyamide structures rise, energy for oxidation is supplied as large, the reaction of dyes and links between polyamide began to take place so as darker color mean intensity value is 1.67 in the lowest color temperature of $90{ }^{\circ} \mathrm{C}$. Thus, polyamide obtained the lowest deviation of color delta E, 2.87, which mean maximum fastness; also it achieved the optimal exhaust of 58.02. So the optimal dyeing temperature in this survey is $90{ }^{\circ} \mathrm{C}$ which is achieved black color and high color fastness.

Effect of time dyeing on the color saturation of polyamide fabric: Figs. 2 (a-c) shows that as time dyeing increased from 30-60 min, the color saturation of dyed polyamide decreased from 2.58 to 1.56 and obtained darker black color gradually. 


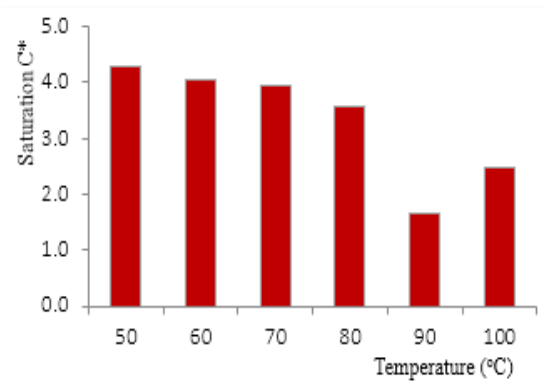

(a)

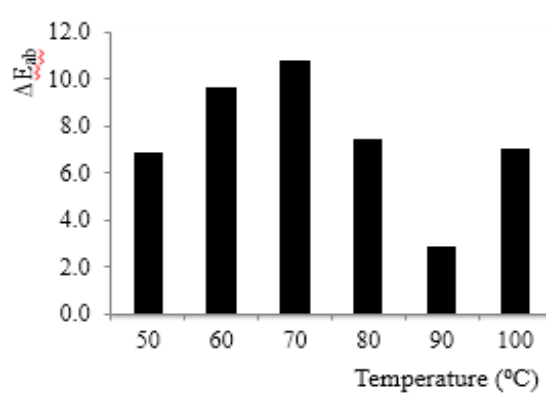

(b)

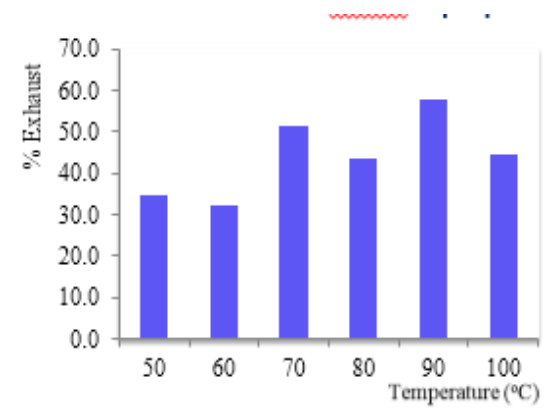

(c)

Fig. 1 Effect of temperature dyeing on color saturation (a) color fastness; (b) and color exhaust; (c) of dyed polyamide fabric by the aqueous extract from Diospyros Mollis.

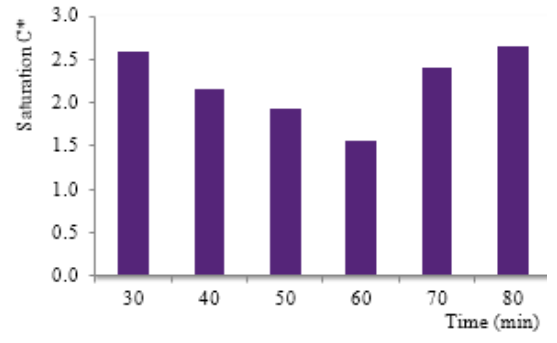

(a)

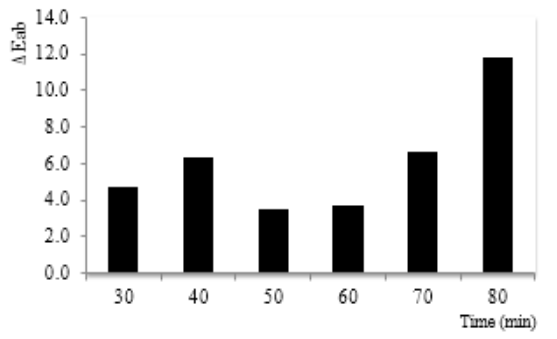

(b)

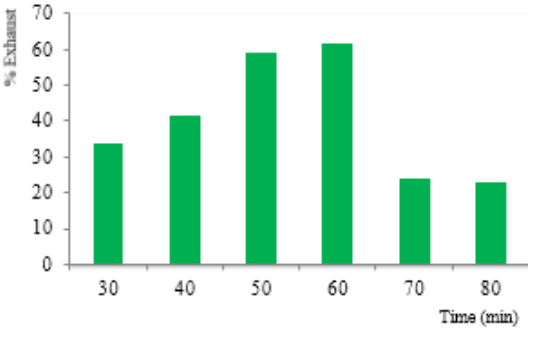

(c)

Fig. 2 Effect of time dyeing on color saturation (a) color fastness; (b) and color exhaust; (c) of dyed polyamide fabric by the aqueous extract from Diospyros Mollis.

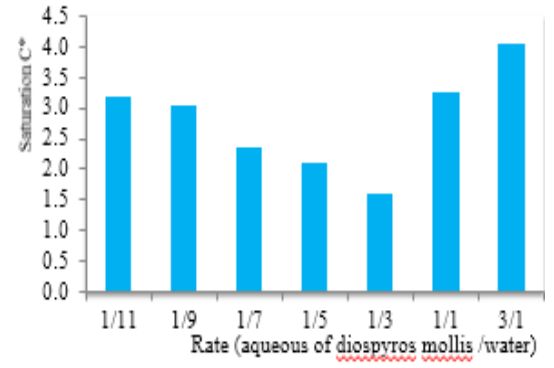

(a)

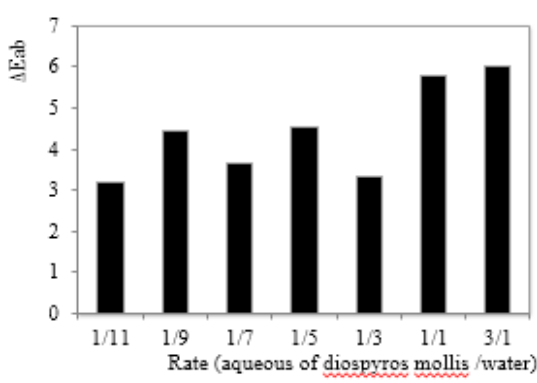

(b)

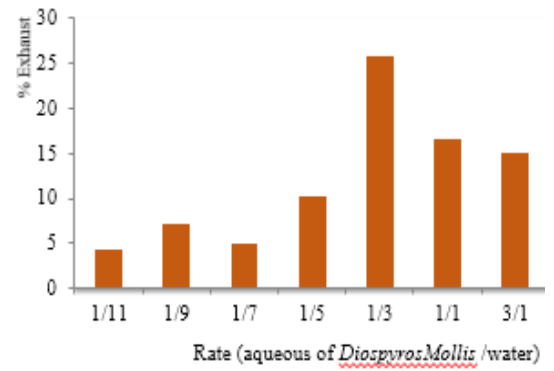

(c)

Fig. 3 Effect of rate dyeing (aqueous of diospyros mollis/water) on color saturation (a) color fastness; (b) and color exhaust; (c) of dyed polyamide fabric by the aqueous extract from Diospyros Mollis.

Between 70-80 min, the color saturation increased, while at $60 \mathrm{~min}$, the color saturation achieved black color and the minimum of color saturation value. Increasing time dyeing increases the response time of fixation between the chromophore compounds with fiber, increasing the number of chromophore compounds linked with cloth so as dark color. In the dyeing process, the compounds in the extract link with fibers form a coating on the surface of fabric, which increases the volume of fabric after dye. Until certain point, the volume will not increase anymore means reaching saturation state. The optimal time dyeing of this survey is 60 minutes, the color saturation is 1.56 , delta $\mathrm{E}$ is 3.66 and the maximum of exhaust is 61.68 , obtaining black color.

Effect of ratedyeing on the color saturation of polyamidefabric: Figs. 3 (a-c) shows that as rate dyeing increase from $1 / 11-1 / 3$, the color saturation of dyed polyamide decreased 3.19-1.59, from 1/1-3/1, the color saturation increasing 3.24-4.03. The optimal time dyeing of this survey is $1 / 3$, the color saturation is 1.59 , delta $\mathrm{E}$ is 3.32 and the maximum of exhaust is 
25.76, obtaining light black color.

3.2 Factorial Experimental Planning Design of Dyeing Polyamide by the Solution Extracted from Diospyros Mollis

Between the variable coding (Xi) and the real variable value ( $\mathrm{Zi}$ ) chosing to study at different levels are interrelated via the Eq. (2):

$$
X_{i}=\frac{Z_{i}-Z_{i}^{o}}{\Delta Z_{i}}
$$

in which:

$Z_{i}^{o}$ : Research value at 0 (rootlevel);

$\Delta Z_{i}$ : The range of variables studied.

$$
\Delta Z_{i}=\frac{Z_{\max }-Z_{\min }}{2}
$$

$\mathrm{Z}_{\text {max }}$ : The value study at high level (+1);

$\mathrm{Z}_{\min }$ :The value study at low $(-1)$.

\begin{tabular}{|l|l|l|l|l|}
\hline \multirow{2}{*}{} & \multirow{2}{*}{ Unit } & \multicolumn{3}{|c|}{ Researchvalue } \\
\cline { 3 - 5 } & & -1 & 0 & +1 \\
\hline $\mathrm{X}_{1}$ & $\%$ rate dyeing/water & 12.5 & 31.25 & 50 \\
\hline $\mathrm{X}_{2}$ & ${ }^{\circ} \mathrm{C}$ & 80 & 90 & 100 \\
\hline
\end{tabular}

Empirical model elements include a total of $2^{2}$ with total experiments of $17(\mathrm{~N}=2 \mathrm{k}+2 \mathrm{k}+3)$, where $\mathrm{k}$ is the number of variables studied $(\mathrm{k}=3)$. Matrix number of original experiments for 2 factor is $2 k=8$ experiments, additional experiments $2 \mathrm{k}=6$ points and 3 stars at center experiment to evaluate the effects of experimental error. With orthogonal plan, $\alpha$ value arm of the matrix is determined by Eq. (4):

$$
\begin{aligned}
\alpha=\sqrt{\sqrt{N .2^{k-2}}}-2^{k-1} & \\
& =\sqrt{\sqrt{17.2^{3-2}}-2^{3-1}} \\
& =1.3
\end{aligned}
$$

From choosing the experimental conditions, it has developed software Statgraphics matrix and obtained the following results:

Analysis of variance and regression: By analysis of experimental results obtained, we assess the extent of the impact of factors related to the polyamide fabric dyeing process using extracts from Diospyros Mollis.
Chart performances Parato effect of factors impact study on the color intensity of dyed polyamide fabric, and letters $\mathrm{A}, \mathrm{B}, \mathrm{C}$ represent the corresponding coding variables: $\mathrm{X}_{1}$ (rate dyeing), $\mathrm{X}_{2}$ (temperature dyeing) and $\mathrm{X}_{3}$ (time dyeing). The column on the chart shows the level of impact of factors linear, quadratic and interaction of these three variables simultaneously. Gray demonstrated interactive effects on color intensity of the fabric, which are positive effects (positive impact increased color intensity of the fabric), and blue is negative effect, reducing the color intensity of the fabric. On the chart, there is a blue line, which is the standardized way with $95 \%$ reliability, helping determine the degree of influence of these factors. The height of the column is the measure of the level of impact as well as the reliability of the factors to target function $\mathrm{Y}$. The columns below the blue line that speaks factors did not significantly influence the intensity of color after dyeing of the fabric and the corresponding regression coefficients in the regression equation would be eliminated by no means.

The regression equation: By the regression Statgraphics software for Eq. (5):

$$
\begin{aligned}
Y=41.97-0.04 & X_{1}-0.92 X_{2}+0.035 X_{3} \\
& +0.00125 X_{1}^{2} \\
& -0.00033 X_{1} X_{2} \\
& +0.00025 X_{1} X_{3} \\
& +0.0064 X_{2}^{2}-0.0035 X_{2} X_{3} \\
& +0.0024 X_{3}^{2}
\end{aligned}
$$

The correlation coefficient value $\left(\mathrm{R}^{2}=0.986758\right)$ indicated that there are $98.6758 \%$ variation in color intensity due to the impact of the independent variables and $1.3242 \%$ due to external factors Prize like being by the model. Values determining correction coefficient (adjustedfor $\mathrm{R}^{2}=0.969733$ ) is very high, demonstrating the high significance of the model. The intensity of color after dyeing polyamide fabric will decrease with increasing concentration and reached the lowest value at $22.035 \%$. Affecting level of concentration is very strong, which is the main impact to the color intensity of the fabric after dyeing. Temperature and time 


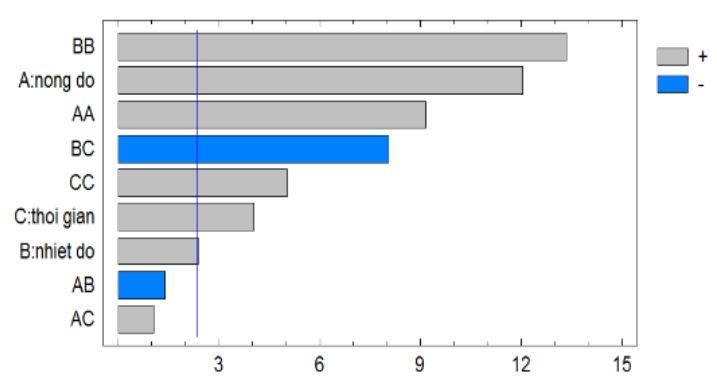

(a)

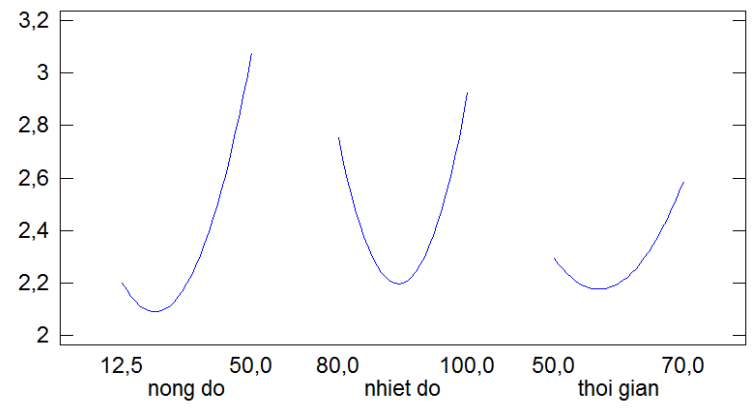

(b)

Fig. 4 Shows the influence of the factors that impact on the objective function of the intensity of color after dye polyamide fabrics.

dyeing are factors that promote the interaction between natural dyes from Diospyrol Mollis into polyamide structure, but not strongly affected by the concentration factor. When temperature and time rise, the color intensity decreases, and the optimum point and the color intensity cannot be further reduced. From the regression equation obtained, the authors conducted optimization polyamide fabric dyeing process using extracts from fruits wear likewise manner RSM software stargraphics. Value for optimal color intensity or saturation is 2.05 and receives parameters optimized single technology temperature dyeing of $87.96{ }^{\circ} \mathrm{C}$, time dyeing of 55.94 and rate dyeing of $1 / 3.5$. Polyamide fabrics after dyeing have been taken to test the criteria for reliability, and the results are obtained as follows: fastness to washing, resistance to sweat; chlorine and friction are achieved at level 4-5, while also achieving ecological criteria as not azo and formadehyde content.

\section{Conclusions}

The study results showed that the level of compatibility between models and experiments is very high, and that the recipe of optimal dyeing technology obtained temperature dyeing is $90{ }^{\circ} \mathrm{C}$; dyeing time is 60 minutes; ratio of extract/water is $1 / 3.5$. This shows that the aqueous extracts from Diospyros Mollis fruits were capable of dyeing polyamide fabrics with high color fastness and obtained color from grey to brown and black. Simultaneously, the advantages of Diospyros Mollisis were environmentally friendly, capable of being renewed and easy to handle garbage, hoping to contribute to green technologies and sustainable development.

\section{References}

[1] Loder, J. W., Mongolsusk, S., Robertson, A., and Whalley, W. B. 1957. "Diospyrol: A Constituent of Diospyros Mollis.” J. Chem. Soc. 2233-2237.

[2] Kien, T., Le Vo S. Q. 2013. "Optimization of Dyeingprocess for Silk Fabricwith Aqueousextracted from the Fruit of Diospyros Mollis." Journal of Science and Technology 51 (5B): 248-252.

[3] Yoshihira, K., Tezuka, M., Kanchanapee, P., and Natori. S. 1971. "Naphthoquinon Derivatives from the Ebenaceae I. Diospyrol and the Related Naphthoquinones from Diospyros Mollis Griff." Chem. Pharm. Bull. 19 (11): 2271-2277.

[4] Pham, T. H. P., Nguyen, T. A. N., Hoang, T. L., Tran, T. K. 2014. "Optimization of Dyeing Process for Silk Fabric with Aqueous Extracted from the Fruit of Diospyros Mollis Using Oxidant." Journal of Science and Technology 52 (5A): 167-174.

[5] Nguyen, C., and Nguyen, D. S. 1994. Empirical Optimization of Chemical and Chemical Engineering. University of Technology: Ho Chi Minh City Publishing House.

[6] Cao, H. T., and Hoang, T. L. 2011. Chemical Dyestuff. New York: Science and Technology Publishing House. 